\title{
Correction to: Post-release behaviors and movements of cultured and wild Japanese eels (Anguilla japonica) in a shallow brackish water lagoon in northeastern Japan
}

\author{
Takuji Noda • Toshihiro Wada • Takashi Iwasaki • \\ Tatsuma Sato • Kaoru Narita • Ikuo Matsumoto • \\ Tomoya Hori • Hiromichi Mitamura • Nobuaki Arai
}

Published online: 25 November 2019

(C) Springer Nature B.V. 2019

\section{Correction to: Environ Biol Fish}

https://doi.org/10.1007/s10641-019-00917-z

The original version of this article unfortunately contained mistakes introduced during the production process. Some of the datetime and date in Tables 1, 2 and 3 were incorrectly shown as "\#\#\#\#\#\#”. The correct Tables are now given below:

The online version of the original article can be found at https://doi. org/10.1007/s10641-019-00917-z

T. Noda $(\bowtie) \cdot$ T. Hori $\cdot$ H. Mitamura

Graduate School of Informatics, Kyoto University,

Kyoto 606-8501, Japan

e-mail: takujinodan@gmail.com

T. Wada

Institute of Environmental Radioactivity, Fukushima University,

Fukushima 960-1296, Japan

T. Iwasaki

Fishery Division of the Fukushima Prefectural Government,

Fukushima 960-8670, Japan

T. Sato

Fukushima Prefectural Inland Water Fisheries Experimental

Station, Inawashiro, Fukushima 969-3283, Japan
K. Narita $\cdot$ I. Matsumoto

Fishery Office of the Fukushima Prefectural Government, Iwaki,

Fukushima 970-8026, Japan

H. Mitamura $\cdot$ N. Arai

CREST, Japan Science and Technology Agency,

Saitama 332-0012, Japan

N. Arai

Field Science and Education and Research Center, Kyoto

University, Kyoto 606-8502, Japan 
Table 1 Details of the tagged cultured and wild Japanese eels (Anguilla japonica) that were used in this study. *1: AP transmitters

\begin{tabular}{|c|c|c|c|c|c|c|c|c|}
\hline ID & Category & $\begin{array}{l}\text { Body mass } \\
\text { (g) }\end{array}$ & $\begin{array}{l}\text { Total length } \\
\quad(\mathrm{mm})\end{array}$ & Released date & $\begin{array}{l}\text { Detection } \\
\text { window } \\
\text { (days) }\end{array}$ & $\begin{array}{r}\text { No of days } \\
\text { detected }\end{array}$ & $\begin{array}{l}\text { Last date } \\
\text { detected }\end{array}$ & $\begin{array}{l}\text { Total no. of } \\
\text { detections }\end{array}$ \\
\hline $\mathrm{CAP}^{*}{ }^{*}$ & Cultured & 480.1 & 637 & Jun 5, 2014 & 13 & 13 & Jun 17, 2014 & 107 \\
\hline $\mathrm{CAP} 2^{* 1}$ & Cultured & 435 & 653 & Jun 5, 2014 & 2 & 2 & Jun 06, 2014 & 44 \\
\hline CAP3 ${ }^{* 1}$ & Cultured & 445.6 & 623 & Jun 5, 2014 & 9 & 3 & Jun 13, 2014 & 64 \\
\hline $\mathrm{CAP} 4^{* 1}$ & Cultured & 448.7 & 665 & Jun 5, 2014 & 124 & 43 & Oct 06,2014 & 259 \\
\hline $\mathrm{CAP}^{*}{ }^{* 1}$ & Cultured & 469.4 & 650 & Jun 5, 2014 & 22 & 12 & Jun 26, 2014 & 67 \\
\hline $\mathrm{CAP}^{* 1}$ & Cultured & 422.4 & 639 & Jun 5, 2014 & 13 & 10 & Jun 17, 2014 & 88 \\
\hline CID1 & Cultured & 327.3 & 605 & Jun 5, 2014 & 278 & 24 & Mar 09, 2015 & 151 \\
\hline CID2 & Cultured & 349.2 & 604 & Jun 5, 2014 & 167 & 55 & Nov 18, 2014 & 240 \\
\hline CID3 & Cultured & 366.6 & 638 & Jun 5, 2014 & 4 & 3 & Jun 08, 2014 & 41 \\
\hline CID4 & Cultured & 327 & 584 & Jun 5, 2014 & 124 & 116 & Oct 06,2014 & 1319 \\
\hline CID5 & Cultured & 377.6 & 634 & Jun 5, 2014 & 162 & 83 & Nov 13, 2014 & 502 \\
\hline CID6 & Cultured & 480.6 & 596 & Jun 5, 2014 & 124 & 17 & Oct 06,2014 & 154 \\
\hline CID7 & Cultured & 362.1 & 593 & Jun 5, 2014 & 136 & 35 & Oct 18,2014 & 528 \\
\hline CID8 & Cultured & 308.2 & 588 & Jun 5, 2014 & 166 & 72 & Nov 17, 2014 & 345 \\
\hline CID9 & Cultured & 359.6 & 586 & Jun 5, 2014 & 173 & 20 & Nov 24, 2014 & 77 \\
\hline CID10 & Cultured & 320.5 & 575 & Jun 5, 2014 & 124 & 99 & Oct 06,2014 & 629 \\
\hline CID11 & Cultured & 347.4 & 611 & Jun 5, 2014 & 73 & 12 & Aug 16, 2014 & 126 \\
\hline CID12 & Cultured & 362.6 & 626 & Jun 5, 2014 & 163 & 96 & Nov 14, 2014 & 2198 \\
\hline CID13 & Cultured & 346.1 & 595 & Jun 5, 2014 & 11 & 5 & Jun 15, 2014 & 23 \\
\hline CID14 & Cultured & 369.5 & 590 & Jun 5, 2014 & 5 & 4 & Jun 09, 2014 & 79 \\
\hline CID15 & Cultured & 343.4 & 590 & Jun 5, 2014 & 124 & 24 & Oct 06,2014 & 128 \\
\hline CID16 & Cultured & 364.3 & 634 & Jun 5, 2014 & 164 & 136 & Nov 15, 2014 & 2869 \\
\hline CID17 & Cultured & 384.4 & 616 & Jun 5, 2014 & 96 & 56 & Sep 08, 2014 & 336 \\
\hline CID18 & Cultured & 339.7 & 607 & Jun 5, 2014 & 124 & 73 & Oct 06,2014 & 472 \\
\hline CID19 & Cultured & 384.5 & 610 & Jun 5, 2014 & 319 & 32 & Apr 19, 2015 & 88 \\
\hline CID20 & Cultured & 353.1 & 595 & Jun 5, 2014 & 5 & 3 & Jun 09, 2014 & 67 \\
\hline CID21 & Cultured & 332.6 & 575 & Jun 5, 2014 & 383 & 111 & Jun 22, 2015 & 631 \\
\hline CID22 & Cultured & 396.8 & 601 & Jun 5, 2014 & 132 & 102 & Oct 14,2014 & 913 \\
\hline CID23 & Cultured & 345.2 & 596 & Jun 5, 2014 & 167 & 33 & Nov 18, 2014 & 302 \\
\hline CID24 & Cultured & 358.6 & 603 & Jun 5, 2014 & 412 & 201 & Jul 21, 2015 & 857 \\
\hline WAP $2^{* 1}$ & Wild & 522.8 & 704 & Jul 15, 2014 & 7 & 5 & Jul 21, 2014 & 33 \\
\hline WAP $3 * 1$ & Wild & 734.37 & 760 & Sep 11, 2014 & 86 & 25 & Dec 05,2014 & 239 \\
\hline WID4 & Wild & 82.2 & 420 & Sep 11, 2014 & 269 & 37 & Jun 06, 2015 & 180 \\
\hline WID5 & Wild & 131.3 & 497 & Sep 11,2014 & 263 & 54 & May 31, 2015 & 272 \\
\hline WID6 & Wild & 441.3 & 692 & Oct 8, 2014 & 287 & 103 & Jul 21, 2015 & 1924 \\
\hline WID7 & Wild & 301.3 & 660 & Oct 8, 2014 & 182 & 9 & Apr 07, 2015 & 77 \\
\hline $\begin{array}{l}\text { Residence } \\
\text { Index } \\
\text { (night) }\end{array}$ & $\begin{array}{l}\text { Residence } \\
\text { Index } \\
\text { (day) }\end{array}$ & $\begin{array}{l}\text { Last Place } \\
\text { Detected }\end{array}$ & $\begin{array}{l}\text { Total No. of } \\
\text { Residency } \\
\text { Event }\end{array}$ & $\begin{array}{c}\text { Total Hour of } \\
\text { Residency } \\
\text { Event (min) }\end{array}$ & $\begin{array}{l}\text { Residency } \\
\text { at North } \\
(\%)\end{array}$ & $\begin{array}{r}\text { Residency at } \\
\text { South }(\%)\end{array}$ & $\begin{array}{c}\text { Residency at } \\
\text { River }(\%)\end{array}$ & $\begin{array}{c}\text { Residency at } \\
\text { Out }(\%)\end{array}$ \\
\hline 0.92 & 0.38 & St28 & 23 & 714 & 3.6 & 96.4 & 0.0 & 0.0 \\
\hline 1.00 & 1.00 & Out2 & 6 & 407 & 100.0 & 0.0 & 0.0 & 0.0 \\
\hline 0.33 & 0.22 & St21 & 14 & 825 & 100.0 & 0.0 & 0.0 & 0.0 \\
\hline 0.27 & 0.15 & St9 & 61 & 2153 & 38.8 & 58.0 & 3.2 & 0.0 \\
\hline
\end{tabular}


Table 1 (continued)

\begin{tabular}{|c|c|c|c|c|c|c|c|c|}
\hline 0.41 & 0.18 & St27 & 15 & 583 & 100.0 & 0.0 & 0.0 & 0.0 \\
\hline 0.46 & 0.46 & St9 & 16 & 639 & 100.0 & 0.0 & 0.0 & 0.0 \\
\hline 0.07 & 0.05 & St20 & 29 & 1192 & 100.0 & 0.0 & 0.0 & 0.0 \\
\hline 0.31 & 0.05 & Out1 & 42 & 1502 & 40.3 & 59.7 & 0.0 & 0.0 \\
\hline 0.75 & 0.75 & Out2 & 8 & 226 & 41.6 & 0.0 & 0.0 & 58.4 \\
\hline 0.90 & 0.43 & Out1 & 295 & 11,202 & 11.4 & 88.4 & 0.0 & 0.1 \\
\hline 0.46 & 0.05 & Out2 & 112 & 3770 & 7.6 & 92.4 & 0.0 & 0.0 \\
\hline 0.13 & 0.09 & Out2 & 31 & 960 & 100.0 & 0.0 & 0.0 & 0.0 \\
\hline 0.24 & 0.18 & St10 & 115 & 4488 & 100.0 & 0.0 & 0.0 & 0.0 \\
\hline 0.39 & 0.11 & Out2 & 69 & 2185 & 10.3 & 89.7 & 0.0 & 0.0 \\
\hline 0.09 & 0.05 & St3 & 16 & 512 & 100.0 & 0.0 & 0.0 & 0.0 \\
\hline 0.70 & 0.14 & Out2 & 142 & 4917 & 5.0 & 95.0 & 0.0 & 0.0 \\
\hline 0.14 & 0.05 & St16 & 27 & 1106 & 98.3 & 1.7 & 0.0 & 0.0 \\
\hline 0.55 & 0.45 & Out & 508 & 20,724 & 3.1 & 96.9 & 0.0 & 0.0 \\
\hline 0.36 & 0.27 & St27 & 5 & 124 & 100.0 & 0.0 & 0.0 & 0.0 \\
\hline 0.60 & 0.80 & St15 & 17 & 779 & 84.7 & 15.3 & 0.0 & 0.0 \\
\hline 0.19 & 0.04 & Out2 & 28 & 729 & 6.2 & 93.8 & 0.0 & 0.0 \\
\hline 0.81 & 0.70 & Out2 & 658 & 24,606 & 98.2 & 0.0 & 0.0 & 1.8 \\
\hline 0.53 & 0.29 & St15 & 76 & 2250 & 6.3 & 88.4 & 5.3 & 0.0 \\
\hline 0.54 & 0.17 & Out1 & 89 & 3107 & 98.0 & 0.0 & 0.0 & 2.0 \\
\hline 0.06 & 0.06 & St16 & 13 & 409 & 18.1 & 81.9 & 0.0 & 0.0 \\
\hline 0.60 & 0.60 & St18 & 13 & 543 & 93.7 & 6.3 & 0.0 & 0.0 \\
\hline 0.21 & 0.10 & St14 & 156 & 4572 & 0.7 & 99.3 & 0.0 & 0.0 \\
\hline 0.72 & 0.28 & Out2 & 185 & 7779 & 3.3 & 96.7 & 0.0 & 0.0 \\
\hline 0.18 & 0.10 & Out2 & 60 & 2323 & 36.2 & 63.8 & 0.0 & 0.0 \\
\hline 0.41 & 0.21 & St15 & 201 & 5891 & 9.3 & 90.7 & 0.0 & 0.0 \\
\hline 0.57 & 0.43 & St15 & 5 & 148 & 25.0 & 75.0 & 0.0 & 0.0 \\
\hline 0.03 & 0.03 & St25 & 45 & 2069 & 6.3 & 93.7 & 0.0 & 0.0 \\
\hline 0.36 & 0.11 & St18 & 35 & 1078 & 3.7 & 80.2 & 16.0 & 0.0 \\
\hline 0.03 & 0.00 & St13 & 59 & 2081 & 3.6 & 96.4 & 0.0 & 0.0 \\
\hline 0.12 & 0.02 & St27 & 401 & 17,470 & 1.0 & 99.0 & 0.0 & 0.0 \\
\hline 0.27 & 0.03 & St30 & 20 & 612 & 32.7 & 67.3 & 0.0 & 0.0 \\
\hline
\end{tabular}

Table 2 Detailed information on the cultured and wild Japanese eels (Anguilla japonica) that were detected in the rivers. Um: Ume River; N: Nikkeshi River; Ud: Uda River; K: Koizumi River

\begin{tabular}{llllll}
\hline Fish ID & First detection time & River & Period after release (day) & Num of detection & Total stay period (day) \\
\hline $\begin{array}{llll}\text { Cultured Eel } \\
\text { CAP4 }\end{array}$ & June 11, 2014, 20:45:27 & Ud & 6.46 & 7 & 0.88 \\
CID2 & October 07, 2014, 18:42:07 & Um & 124.38 & 1 & 0.04 \\
CID5 & June 10, 2014, 01:47:56 & Um & 4.67 & 1 & 0.03 \\
CID9 & June 11, 2014, 21:52:46 & K & 6.51 & 1 & 0.02 \\
CID11 & June 11, 2014, 03:28:39 & Um & 5.74 & 1 & 0.69 \\
CID11 & June 12, 2014, 23:58:30 & Um & 7.60 & 1 & 0.12 \\
CID17 & June 10, 2014, 21:28:30 & $\mathrm{N}$ & 5.49 & 3 & 0.12 \\
CID17 & June 11, 2014,00:39:05 & $\mathrm{N}$ & 5.63 & 1 & 0.04 \\
CID17 & June 11, 2014, 02:10:36 & $\mathrm{N}$ & 5.69 & 3 & 0.02 \\
CID17 & June 11, 2014, 03:21:39 & $\mathrm{N}$ & 5.74 & 1 & 0.57 \\
CID22 & July 20, 2014, 21:24:10 & Um & 45.49 & 2 & 0.15 \\
CID22 & October 06, 2014, 21:01:38 & Um & 123.48 & 1 & 0.16 \\
CID22 & October 08, 2014, 01:56:28 & Um & 124.68 & & 0.04
\end{tabular}


Table 2 (continued)

\begin{tabular}{clllll}
\hline Fish ID & First detection time & River & Period after release (day) & Num of detection & Total stay period (day) \\
\hline Wild Eel & & & & & \\
WAP2 & July 17, 2014, 20:51:48 & Um & 2.14 & 1 & 0.01 \\
WID4 & September 13, 2014, 21:39:23 & N & 4.17 & 11 & 0.85 \\
WID4 & September 15, 2014, 20:12:57 & N & 8.22 & 1 & 3.29 \\
WID4 & September 22, 2014, 01:13:23 & Um & 164.51 & 1 & 0.01 \\
WID4 & October 15, 2014, 18:52:55 & Um & 2.26 & 1 & 0.97 \\
WID4 & October 16, 2014, 18:13:58 & Um & 4.20 & 2 & 0.08 \\
WID4 & April 16, 2015, 03:02:18 & Um & 10.41 & 1 & 3.01 \\
WID5 & November 04, 2014, 23:57:27 & Um & 34.14 & 1 & 0.02 \\
WID6 & October 12, 2014, 18:50:05 & Um & 35.12 & 1 & 0.01 \\
WID6 & October 16, 2014, 19:58:18 & Um & 216.48 & 0.02 \\
WID7 & March 22, 2015, 02:59:57 & Um & 54.35 & 1 & 120.88 \\
\hline
\end{tabular}

Table 3 Environments at the time of last detection and movement speeds of the cultured Japanese eels (Anguilla japonica) that undertook seaward migration. NA indicates 'not applicable'

\begin{tabular}{|c|c|c|c|c|c|c|c|c|c|}
\hline ID & Last day detected & $\begin{array}{l}\text { Last time } \\
\text { detected }\end{array}$ & $\begin{array}{l}\text { Temperature } \\
\left({ }^{\circ} \mathrm{C}\right)\end{array}$ & $\begin{array}{l}\text { Salinity } \\
\text { (psu) }\end{array}$ & $\begin{array}{l}\text { Total rain in } \\
\text { a day }(\mathrm{mm})\end{array}$ & Tide & $\begin{array}{l}\text { Speed } \\
(\mathrm{km} / \mathrm{h})\end{array}$ & $\begin{array}{l}\text { Moon } \\
\text { age }\end{array}$ & $\begin{array}{l}\text { Name of } \\
\text { typhoon }\end{array}$ \\
\hline CID2 & November 18, 2014 & 18:08:20 & 12.1 & 31.9 & 0.0 & ebb & 2.9 & 25.2 & NA \\
\hline CID4 & October 6, 2014 & $17: 22: 32$ & 18.1 & 23.8 & 146.0 & ebb & 3.1 & 11.9 & No.18 \\
\hline CID5 & November 13, 2014 & $20: 41: 53$ & 14.9 & 32.3 & 0.0 & ebb & 0.8 & 20.2 & NA \\
\hline CID6 & October 6, 2014 & $18: 23: 47$ & 17.7 & 21.9 & 146.0 & ebb & 5.2 & 11.9 & No.18 \\
\hline CID8 & November 17, 2014 & $17: 21: 53$ & 13.5 & 32.2 & 0.0 & ebb & 0.2 & 24.2 & NA \\
\hline CID10 & October 6, 2014 & $18: 22: 02$ & 17.7 & 21.9 & 146.0 & $\mathrm{ebb}$ & 0.3 & 11.9 & No.18 \\
\hline CID12 & November 14, 2014 & $18: 28: 57$ & 15.3 & 32.6 & 0.0 & flood & 1.8 & 21.2 & NA \\
\hline CID15 & October 6, 2014 & $18: 25: 34$ & 17.7 & 21.9 & 146.0 & ebb & 2.6 & 11.9 & No.18 \\
\hline CID16 & November 15, 2014 & $18: 23: 40$ & 14.1 & 32.2 & 0.0 & flood & 2.2 & 22.2 & NA \\
\hline CID18 & October 6, 2014 & $18: 14: 55$ & 17.7 & 21.9 & 146.0 & ebb & NA & 11.9 & No.18 \\
\hline CID22 & October 14, 2014 & 19:39:46 & 18.3 & 21.1 & 108.0 & ebb & 3.3 & 19.9 & No.19 \\
\hline CID23 & November 18, 2014 & $17: 46: 26$ & 12.8 & 32.1 & 0.0 & ebb & 4.5 & 25.2 & NA \\
\hline
\end{tabular}

The original article has been corrected.

Publisher's note Springer Nature remains neutral with regard to jurisdictional claims in published maps and institutional affiliations. 